\title{
Knowledge on Mother to Child Transmission and Utilization of Services Designed to Prevent Mother to Child Transmission of HIV/AIDS among Pregnant Women in Hossana Town, Southern Ethiopia
}

\author{
Belayneh Hamdela ${ }^{1 *}$, Fregenet Zekiewos ${ }^{1}$ and Tigist Workneh ${ }^{2}$ \\ ${ }^{1}$ Department of public health, faculty of medicine and health sciences, Wachemo University, Hossana, Ethiopia \\ ${ }^{2}$ Department of Medicine, faculty of medicine and health sciences, Wachemo University, Hossana, Ethiopia
}

*Corresponding author: Belayneh Hamdela, Department of public health, faculty of medicine and health sciences, Wachemo University, P. O. Box 667, Hossana, Ethiopia, Tel: +251945845544; E-mail: belaynehhamdala@yahoo.com

Received date: October 16, 2014; Accepted date: November 27, 2014; Published date: December 02, 2014

Copyright: ( 2014 Hamdela B, et al. This is an open-access article distributed under the terms of the Creative Commons Attribution License, which permits unrestricted use, distribution, and reproduction in any medium, provided the original author and source are credited.

\begin{abstract}
Background: Every day, more than 1,800 babies worldwide contract HIV from their mothers. Many of these cases occur in Africa including Ethiopia. The transmission of HIV from infected mothers to babies could occur during pregnancy, delivery and breastfeeding. For women to take advantage of measures to reduce transmission, they need to know about Mother To Child Transmission (MTCT) of HIV and their HIV status. The aim of this study was to assess the knowledge on MTCT and utilization of services designed for Prevention of Mother-To-Child Transmission (PMTCT) of HIVIAIDS among pregnant women.
\end{abstract}

Methods: Community based cross-sectional study was conducted at Hossana town from March 3-28/ 2014 using pre-tested questionnaire and structured interviews. The collected data were analyzed using SPSS version 16. Descriptive statistics and logistic regression analysis were done.

Result: Out of the 417 pregnant women interviewed, 370 (88.7\%) responded that they know MTCT of HIV, $377(90.4 \%)$ mothers tested for HIV during current pregnancy and 354(93.9\%) shared test result to their husband. Few, $23(6.1 \%)$ did not disclose test result due to fear of divorce. The main reason for HIV testing, according to this study, is to know self-status. Knowledge of Mother to child transmission was the independent predictor of utilization of the services rendered for PMTCT of HIVIAIDS.

Conclusions: More than three-fourth of pregnant women knew about MTCT of HIV. Nine women in every ten tested for HIV during current pregnancy and shared test result to their husband. Knowledge of mother to child transmission of HIVIAIDS was the independent predictor of utilization of PMTCT services. Thus, improving awareness of pregnant women about MTCT of HIVIAIDS and its prevention strategies by means of health care providers in maternal and child health service units should be strengthened.

Keywords: Knowledge of MTCT; Utilization of PMTCT of HIV/ AIDS; Pregnant women; Hossana; South Ethiopia

\section{Abbreviations}

HIV: Human Immunodeficiency Virus; AIDS: Acquired Immunodeficiency Syndrome; PMTCT: Prevention of Mother To Child Transmission; ART: Anti-Retroviral Treatment; ANC: Ante Natal Care; AOR: Adjusted Odds Ratio; CI: Confidence Interval; EDHS: Ethiopia Demographic and Health Survey; IEC: Information Education and Communication; BCC: Behaviour Change Communication; Km: Kilometer.

\section{Introduction}

Mother-To-Child Transmission (MTCT) accounts for the vast majority of more than 700,000 estimated new HIV infections in children worldwide annually [1]. Every day, more than 1800 babies contract HIV from their mothers worldwide; and many of these cases occur in Africa [2]. The probability of infection from mothers who do not receive treatment is higher in Africa (25\% - 52\%) than the United
States (US) or Europe (12\%-30\%) [2].Coverage of pregnant women receiving the most effective antiretroviral regimens to prevent motherto-child transmission of HIV (excluding single-dose nevirapine) was estimated up to $48 \%$ in 2010 [3].

Ethiopia is one of the seriously affected countries in sub-Saharan Africa with a large number of people who are living with HIV/AIDS and AIDS-related deaths [4]. An estimated number of 249,174 adults (86\% of eligible) are on ART treatment [4]. In developing countries including Ethiopia, mother to child transmission has become a critical child health problem. It creates enormous social and economic problems.

The reasons for an increasing mother to child transmission of HIV might include lack of knowledge of mothers on the risk of mother to child transmission, benefits of preventive interventions such as prophylactic antiretroviral drugs and infant feeding options [5]. Since most efforts are donor driven and are readily accessible in urban centres, prevention of mother to child transmission service uptake is still low in Ethiopia. According to Ethiopian Demographic and Health Survey (EDHS) 2011, only 34\% and $10 \%$ of mothers had antenatal care follow up and skilled attendant at delivery respectively having a 
Citation: Hamdela B, Zekiewos F, Workneh T (2014) Knowledge on Mother to Child Transmission and Utilization of Services Designed to Prevent Mother to Child Transmission of HIVIAIDS among Pregnant Women in Hossana Town, Southern Ethiopia. J AIDS Clin Res 5: 396. doi:10.4172/2155-6113.1000396

Page 2 of 8

negative contribution on utilization of prevention of mother to child transmission services [6].

Without any interventions, between $20 \%$ and $45 \%$ of infants may become infected: $5-10 \%$ during pregnancy, $10-20 \%$ during labour and delivery and $5-20 \%$ through breastfeeding [7]. The overall risk can be reduced to less than $2 \%$ by a package of evidence-based interventions [7].

To optimize the effectiveness of prevention of mother to child transmission of HIV/AIDS, World Health Organization (WHO) promotes a four-pronged comprehensive approach which is aimed at improving maternal and child health in the context of HIV epidemic. This approach promotes routine HIV testing and counselling for pregnant women. If a woman found to be HIV positive wants to continue her pregnancy, she should receive clinical management and Highly Active Anti-Retroviral Treatment (HAART) for herself, if eligible or at least antiretroviral prophylaxis. For those who want to terminate their pregnancy, safe abortion should be offered where available. Pregnant women should also receive counselling on safe infant feeding choices and appropriately referred for continued care for themselves and their children after delivery [8].

A study from Nigeria revealed that $74.5 \%$ of pregnant women were aware of mother to child transmission of HIV [9]. A study from Hawassa (Ethiopia) also revealed that about $96 \%$ of mothers have been tested for HIV and the rest did not test mainly due to fear of stigma, discrimination and lack of confidentiality. In addition, the finding indicated that delivery at Health Centre and antenatal care visit of four and above for the most recent pregnancy found to have statistically significant association with practice of prevention of mother to child transmission of HIV/AIDS services [5].

Reviewed literatures revealed that there are limited studies on utilization of services rendered for prevention of mother to child transmission of HIV/AIDS and its associated factors in different places with varied access to information and services that enable the pregnant women to seek prevention options for mother to child transmission of HIV in Ethiopia.

Better knowledge of mother to child transmission, its prevention and practicing the services rendered for prevention of mother to child transmission is highly effective intervention. For, it has an enormous potential to improve both maternal and child health. Therefore, this study was aimed to assess the knowledge of pregnant women about mother to child transmission of HIV/AIDS, utilization of services intended to prevent mother to child transmission of HIV/AIDS and determinant factors for utilization of services rendered to prevent mother to child transmission of HIV/AIDS. Thus, the results of this study will help to improve utilization of services designed to prevent mother to child transmission of HIV/AIDS in the study area and other areas in the country. It will also enable pregnant women know their status, seek early intervention and adhere to their treatment.

Moreover, the results of this study optimistically help healthcare institutions to recognize mother's knowledge on mother to child transmission and utilization of prevention of mother to child transmission of HIV/AIDS. Hence, the findings provide accurate information on risk of mother to child transmission, availability of prevention options, and effect of HIV on pregnancy outcomes and involvement and screening of partner to improve quality care.

\section{Methods and materials}

\section{Study setting}

The study was carried out in Hossana town, Hadiya administrative zone, South Ethiopia which is located $230 \mathrm{~km}$ from the capital city of Ethiopia, Addis Ababa and $194 \mathrm{~km}$ from the regional capital city, Hawassa. It is one of the eleven districts found in the zone. It has purely woinedega agro ecological zone. It is situated at an altitude of 1800-2950 meters above sea level and has an average temperature ranging from $10 \mathrm{octo} 24 \mathrm{oc}$. The annual rain fall is $1250 \mathrm{~mm}$ per year.

Based on the 2007 Ethiopian national population and housing census the population of the town is projected to be about 78,432: male 38,800 and female 39,632 . Number of child bearing age women (15-49 years) is 18,275 (Hossana town administrative office report). In Hossana town, there are one youth friendly service, three health centres, one zonal Hospital, sixteen private clinics and twenty two drug shops. There are also non-governmental organizations working with town's health bureau such as USAID/JSI/ and Marie stopes international. Data was collected from March 3-28/ 2014.

\section{Study design}

Community based cross-sectional study using quantitative method of data collection was employed.

\section{Population}

The target populations for this study were all pregnant women who resided in hossana town for at least six months prior to the survey. The study populations were sample pregnant women who were randomly selected from target population.

\section{Sample size determination and sampling technique}

To determine the sample size, a single population proportion formula using the proportion of pregnant women who practiced services rendered for prevention of mother to child transmission of HIV/AIDS assumed to be $50 \%$, a confidence level of $95 \%$, and a $5 \%$ degree of precision. A non-response rate of $10 \%$ was also added. The Final sample size calculated was 422 .

Hossana town has three sub-towns namely Sechuduna, Gofermeda and Addis ketema. Each of this sub-town has kebeles (the smallest administrative unit in Ethiopia). In order to select representative number of study participants from each of this kebele, census was conducted in all kebeles of the sub-towns. First, recording was done by Health Extension Workers (a kind of health care providers who provide a range of community health services in areas where medical personnel are limited) in each kebeles to know the number of pregnant women. Then proportional allocation to the size of pregnant women was given to each kebele. Finally, simple random sampling method was used to select the required number of pregnant women from each kebele (Table 1 and Figure 1).

\begin{tabular}{|l|l|l|l|l|}
\hline Hossana town (sub-towns) & Total kebeles & $\begin{array}{l}\text { Total no of pregnant } \\
\text { women }\end{array}$ & $\begin{array}{l}\text { Proportional allocation to size of pregnant } \\
\text { women }\end{array}$ & $\begin{array}{l}\text { Percentage of pregnant women } \\
\text { participated from each kebele }\end{array}$ \\
\hline
\end{tabular}


Citation: Hamdela B, Zekiewos F, Workneh T (2014) Knowledge on Mother to Child Transmission and Utilization of Services Designed to Prevent Mother to Child Transmission of HIVIAIDS among Pregnant Women in Hossana Town, Southern Ethiopia. J AIDS Clin Res 5: 396. doi:10.4172/2155-6113.1000396

Page 3 of 8

\begin{tabular}{|l|l|l|l|l|}
\hline \multirow{5}{*}{ SECHDUNA } & Arada & 457 & $457 \times 422 / 3499=55$ & $13.06 \%$ \\
\cline { 2 - 5 } & Sechiduna & 439 & $439 \times 422 / 3499=53$ & $12.55 \%$ \\
\cline { 2 - 5 } & Bethel & 403 & $403 \times 422 / 3499=49$ & $11.52 \%$ \\
\hline \multirow{5}{*}{ GOFERMEDA } & Bobicho & 435 & $435 \times 422 / 3499=52$ & $12.43 \%$ \\
\cline { 2 - 5 } & Jalunaramo & 415 & $415 \times 422 / 3499=50$ & $11.86 \%$ \\
\cline { 2 - 5 } & Heto & 385 & $385 \times 422 / 3499=46$ & $11 \%$ \\
\hline ADDIS KETEMA & Mele'amba & 486 & $486 \times 422 / 3499=59$ & $13.89 \%$ \\
\cline { 2 - 5 } & Lichamba & 479 & $479 \times 422 / 3499=58$ & $13.69 \%$ \\
\hline Total & 8 & 3499 & 422 & $100 \%$ \\
\hline
\end{tabular}

Table 1: Proportional allocation to the size of pregnant women in each kebele of Hossana town, March 2014.

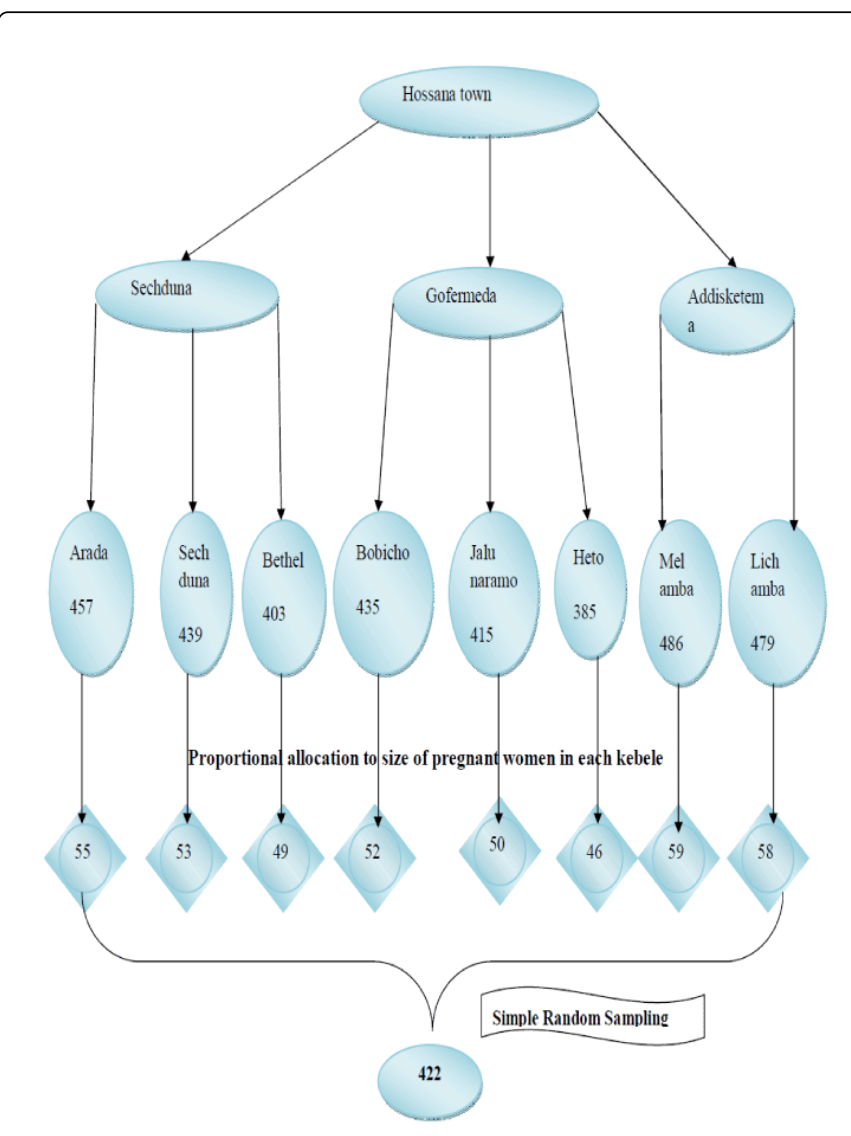

Figure 1: Schematic presentation of sampling procedure for the study in hosanna town, March 2014.

\section{Data collection}

\section{Instrument}

Pre-tested questionnaire and structured interviews were adapted from previous studies $[5,6,8,9]$. Reviewing relevant literatures to the problem under study tried to include all possible variables that address the objective of the study. The questionnaire contained a combination of open ended and closed ended questions. It was also designed to obtain information on socio-demographic and economic characteristics, knowledge about HIV/AIDS, knowledge on mother to child transmission, practice and factors associated with practice of services intended for prevention of mother to child transmission of HIV/AIDS. The questionnaire were prepared in English and translated to Amharic language. Two days training was given for data collectors and supervisors on the objective of the study. Data collectors were diploma nurses and the supervisors were Bachelor of Science (BSc) holders in nursing, midwifery and public health. Data collectors and supervisors were intentionally selected from Hossana born individuals who know the local culture and languages. The questionnaire was pretested on 5\% (42 pregnant women) of respondents in kebeles having similar socio demographic characteristics with the target participants and minor modification was made accordingly. Finally, data were collected by face to face interview.

\section{Data analysis and presentation}

The collected data were checked manually for its completeness and consistency by supervisors during field work and rechecked again at office by investigators before data entry. Then data were entered to Statistical Package for Social Science (SPSS) window versions 16.0. Entered data were explored to check outliers, missing values and cleaned before analysis. Finally, descriptive statistics (frequency tables) were done to summarize data and bivariate analysis was done to see the association of individual explanatory variables to outcome variable. Based on the findings of bivariate analysis, variables having significant association $(\mathrm{P}<0.05)$ with outcome variable were entered to multivariate logistic regression analysis using enter method to identify independent socio-demographic, economic, maternal health service and HIV/AIDS related predictors of the outcome variable. Finally, Pvalue less than 0.05 in multivariate analysis was used to declare association between independent predictors and the outcome variable.

\section{Ethical consideration}

Ethical approval was obtained from ethical review committee of Wachemo University, faculty of medicine and health sciences and department of public health. Participants were informed and given full rights and freedom to participate in the study or not to participate. Privacy and confidentiality were maintained during interview. The 
Citation: Hamdela B, Zekiewos F, Workneh T (2014) Knowledge on Mother to Child Transmission and Utilization of Services Designed to Prevent Mother to Child Transmission of HIVIAIDS among Pregnant Women in Hossana Town, Southern Ethiopia. J AIDS Clin Res 5: 396. doi:10.4172/2155-6113.1000396

Page 4 of 8

participants were told that any information they provided would be kept confidential. Participant's name and house number never appeared on data collection tools. Besides, the study participants were informed that their responses would not result in any harm to them. The purpose, general content and nature of the investigation were explained to each respondent to obtain a verbal consent before inclusion into the study. Questions and concerns raised by the participants were clarified. Finally, the participants who agreed to give their data were included in the study.

\section{Results}

\section{Socio-demographic and economic characteristics}

A total of 417 pregnant women responded to the questionnaire, yielding a response rate of $98.8 \%$. More than half of the respondents 228 (54.7\%) were between 25-34 years of age. The mean age was found to be $17.6(S D+6.36)$ years with a median of 20 . One hundred and sixty eight $(40.3 \%)$ of the participants had a family size of 5 and above with the mean as 2.17 (SD+.78). Two-hundred and fourteen (51.3\%) were protestants in religion. Two hundred and twenty (52.8\%) were Hadiya in ethnic group. Four hundred and ten (98.3\%) were married at the time of the survey. Thirty-six $(8.6 \%)$ women were unable to read and write, $47(11.3 \%)$ women were able to read and write, $118(28.3 \%)$ attended primary (grade 1-8), 130(31.2\%) attended secondary (grade 9-12) and $86(20.6 \%)$ were in higher education (above grade 12). Majority of their husband $157(38.1 \%)$ were in higher education. One hundred and eight-five (44.4\%) women were housewives, 77(18.5\%) were government employees, $70(16.8 \%)$ were venders and $34(8.2 \%)$ were private employees and 27(6.5\%) were students. One hundred and fifty two (36.5\%) husband of the women were government employees, $116(27.8 \%)$ were venders, $51(12.2 \%)$ were private employees and 37 (8.9\%) were farmers (Table 2).

\begin{tabular}{|c|c|c|}
\hline Variables & Frequency & $\%$ \\
\hline \multicolumn{3}{|l|}{ Age } \\
\hline $15-24$ & 141 & 33.8 \\
\hline $25-34$ & 228 & 54.7 \\
\hline 35 and above & 48 & 11.5 \\
\hline \multicolumn{3}{|l|}{ Family size } \\
\hline $1-2$ & 99 & 23.7 \\
\hline $3-4$ & 150 & 36 \\
\hline 5 and above & 168 & 40.3 \\
\hline \multicolumn{3}{|l|}{ Religion } \\
\hline Orthodox & 101 & 24.2 \\
\hline Musilim & 52 & 12.5 \\
\hline Protestant & 214 & 51.3 \\
\hline Catholic & 39 & 9.4 \\
\hline Appopolistic & 11 & 2.6 \\
\hline \multicolumn{3}{|l|}{ Ethnicity } \\
\hline Hadiya & 220 & 52.8 \\
\hline
\end{tabular}

\begin{tabular}{|c|c|c|}
\hline Guragie & 52 & 12.5 \\
\hline Cambata & 85 & 20.4 \\
\hline Silite & 33 & 7.9 \\
\hline Amhara & 26 & 6.2 \\
\hline Oromo & 1 & 0.2 \\
\hline \multicolumn{3}{|l|}{ Marital status } \\
\hline Married & 410 & 98.3 \\
\hline Unmarried & 3 & 0.7 \\
\hline Divorced & 2 & 0.5 \\
\hline Widowed & 2 & 0.5 \\
\hline \multicolumn{3}{|l|}{ Husband's education } \\
\hline Can't read and write & 5 & 1.2 \\
\hline Read and write & 26 & 6.3 \\
\hline Primary (grades 1-8) & 96 & 23.3 \\
\hline Secondary(grades 9-12) & 128 & 31.1 \\
\hline Higher (above grade 12) & 157 & 38.1 \\
\hline \multicolumn{3}{|l|}{ Women occupation } \\
\hline Housewife & 185 & 44.4 \\
\hline Government employed & 77 & 18.5 \\
\hline Vender & 70 & 16.8 \\
\hline Private employed & 34 & 8.2 \\
\hline Student & 27 & 6.5 \\
\hline Other $\square$ & 24 & 5.8 \\
\hline
\end{tabular}

Table 2: Socio-Demographic and Economic Characteristics of Pregnant Women in Hossana Town, South Ethiopia, March 2014.

\section{Reproductive health history}

The mean ages at marriage were $19.8(\mathrm{SD}+2.67)$ with a median of 20 years. Two hundred and seventy-seven $(66.9 \%)$ had been married at the age of 18 and above while $137(33.1 \%)$ had been married at the age of less than 18 years. The mean duration of marriage was 7.25(SD +5.37). Two hundred (48\%) of pregnant women were multipara. According to the respondents, 62 (14.9\%) of the women delivered their recent child at home while $254(60.8 \%)$ delivered at health facilities 157 (37.6\%) in hospital, 54(12.9\%) in health centres and 43 (10.3\%) delivered at private clinics). Two hundred and one (48.2\%) women were in third trimester pregnancy. Two hundred and ninety $(69.5 \%)$ were visited health facility seeking ante natal care for their most recent child birth. However, majority $374(89.7 \%)$ of the pregnant women reported that they were visiting health facility for ante natal care currently (Table 3 ).

\begin{tabular}{|l|l|l|}
\hline Variables & Frequency & $\%$ \\
\hline Parity & & \\
\hline
\end{tabular}


Citation: Hamdela B, Zekiewos F, Workneh T (2014) Knowledge on Mother to Child Transmission and Utilization of Services Designed to Prevent Mother to Child Transmission of HIVIAIDS among Pregnant Women in Hossana Town, Southern Ethiopia. J AIDS Clin Res 5: 396. doi:10.4172/2155-6113.1000396

Page 5 of 8

\begin{tabular}{|c|c|c|}
\hline Null para & 109 & 26.1 \\
\hline Para I & 77 & 18.5 \\
\hline Multi-para & 200 & 48 \\
\hline Grand multi-para & 31 & 7.4 \\
\hline \multicolumn{3}{|c|}{ Duration of pregnancy } \\
\hline 1st trimester & 24 & 5.8 \\
\hline 2nd trimester & 187 & 44.8 \\
\hline 3rd trimester & 201 & 48.2 \\
\hline Don't know & 5 & 1.2 \\
\hline \multicolumn{3}{|c|}{ History of previous antenatal care visit } \\
\hline Yes & 290 & 69.5 \\
\hline No & 35 & 8.4 \\
\hline Primigravida & 92 & 22.1 \\
\hline \multicolumn{3}{|c|}{ Current antenatal care visit } \\
\hline Yes & 374 & 89.7 \\
\hline No & 43 & 10.3 \\
\hline \multicolumn{3}{|c|}{ No of current antenatal care visit } \\
\hline One & 116 & 31.0 \\
\hline Two & 124 & 33.2 \\
\hline Three & 81 & 21.7 \\
\hline Four and above & 53 & 14.2 \\
\hline
\end{tabular}

Table 3: Reproductive health history of Pregnant Women in Hossana Town, South Ethiopia, March 2014.

Other $*$ : farmer, religious works, etc.

\section{Knowledge of Pregnant Women on Mother-to-Child Transmission of HIV}

This study attempted to assess pregnant women's knowledge regarding modes of transmission particularly mother to child transmission of HIV in Hossana town. Majority of the respondents, 410(98.3\%) heard about HIV/AIDS. However, few 7(1.7\%) of them responded that they did not hear about HIV/AIDS. Three hundred forty-seven $(83.2 \%)$ of the respondents knew at least one mode of HIV transmission, 57(13.7\%) of them knew the four modes (unprotected sexual intercourse, mother to child, blood transfusion and contaminated instruments) and the rest 13(3.1\%) didn't know any mode of HIV transmission.

Respondents were assessed whether they know mother to child transmission of HIV or not. As a result, 370(88.7\%) of them responded that they knew mother to child transmission of HIV and the rest $47(11.3 \%)$ responded as they did not know it. Out of the 370 respondents who knew mother to child transmission of HIV, $271(73.24 \%)$ knew at least one (either during pregnancy, labour and delivery or during breast feeding), 73(19.73\%) knew all the three times (pregnancy, labour and delivery and breast feeding) that the child

acquires HIV from the mother, and 26(7.03\%) responded as they did not know the time that the child takes risk. Generally, 368(88.2\%) respondents had good knowledge (greater than average score) and 49 (11.8\%) had poor knowledge (below average score) on mother to child transmission of HIV.

Concerning knowledge on prevention of mother to child transmission of HIV (PMTCT), 326(78.2\%) knew that the risk of mother to child transmission of HIV can be prevented and the rest 91(21.8\%) responded that it is impossible to prevent the transmission once a mother is infected with HIV. Two hundred fifty-five $(61.2 \%)$ responded that they heard about antiretroviral drugs whereas the rest162 (38.8\%) responded as they did not hear about antiretroviral drugs.

\section{Practice towards prevention of mother to child transmission (PMTCT) of HIV}

Four hundred two (96.4\%) of the respondents were aware of HIV testing and counselling though the rest 15 (3.6\%) were not aware of it. Majority of the respondents, $377(90.4 \%)$ were tested for HIV during current pregnancy and 40(9.6\%) were not tested. Out of the 377 who were tested, 376(99.2\%) knew their HIV status: 156 (41.7\%) get tested in the first trimester, 201(53.7\%) in second trimester and the rest $17(4.5 \%)$ in third trimester of their pregnancy. Three hundred and fifteen $(84.2 \%)$ were tested during first visit, $40(10.7 \%)$ during second visit, $13(3.5 \%)$ during third visit and the rest 6(1.6\%) were tested during fourth visit of antenatal care. The main reason for HIV testing was to know self-status as responded by most of the respondents, 348(92.3\%). Among the 377 respondents who were tested, 354(93.9\%) disclosed the result of testing for their partner/husband whereas the rest 23(6.1\%) didn't disclose the result of testing. The main reason for not disclosing test result, as per the response of the few participants $6(26.1 \%)$ was fear of divorce. One hundred ninety-four $(51.59 \%)$ were counselled alone, $137(36.44 \%)$ were counselled together with their couples and the rest 45 (11.97\%) were counselled in group for testing during the current pregnancy. Three hundred seventy (98.1\%) of the respondents were satisfied by the service provided in the health facility.

Concerning the HIV status of their husband/partner, women participants responded that 227(58.5\%) of husband/partner were tested during current pregnancy. Two hundred eighty-two $(67.6 \%)$ of the pregnant women had discussed with their husband about HIV testing during current pregnancy. One hundred forty-three $(34.3 \%)$ of the respondents ever participated on HIV/AIDS issues during community conversation. Respondents were asked about the feelings of their husbands about HIV testing during pregnancy. Accordingly, 267(66.9\%) responded that their husbands are willing for testing, $110(27.6 \%)$ responded that their husbands support only wife testing, $10(2.5 \%)$ responded that they do not support both testing, and the rest $12(3 \%)$ are not willing to respond about their partners'/husbands' feeling. Generally, 377(90.4\%) respondents practiced on services rendered for prevention of mother to child transmission of HIV and the rest $40(9.6 \%)$ didn't practice.

\section{Factors associated with practice of PMTCT of HIV/AIDS}

Practice of services designed for Prevention of Mother to Child Transmission (PMTCT) of HIV was assessed for its association with socio-demographic, economic and reproductive variables. Bivariate analysis in the binary logistic regression model had shown no 
Citation: Hamdela B, Zekiewos F, Workneh T (2014) Knowledge on Mother to Child Transmission and Utilization of Services Designed to Prevent Mother to Child Transmission of HIVIAIDS among Pregnant Women in Hossana Town, Southern Ethiopia. J AIDS Clin Res 5: 396. doi:10.4172/2155-6113.1000396

Page 6 of 8

association between socio-demographic and economic variables such as age, education, family size, religion, occupation, marital status and ethnicity with practice of services rendered for prevention of mother to child transmission of HIV/AIDS. Reproductive characteristics of pregnant women such as previous history of antenatal care visit, knowledge of mother to child transmission of HIV, knowledge on time of mother to child transmission of HIV, awareness on HIV counselling and testing as well as discussion with husband about HIV/ AIDS issues were significantly associated with practice of services designed for prevention of mother to child transmission of HIV/AIDS at $\mathrm{p}$-value $<0.05$.
In the multivariate analysis, adjusting for possible confounding variables, most of reproductive characteristics of pregnant women had shown no significant association with practice of PMTCT of HIV/ AIDS. However, knowledge of mother to child transmission of HIV had shown statistically significant association with practice of services designed for prevention of mother to child transmission of HIV. Accordingly, women who knew mother to child transmission of HIV [AOR=5.74, 95\%CI: $1.02,32.21$ ] were more likely to practice services designed for prevention of mother to child transmission of HIV/AIDS than their counter parts (Table 4).

\begin{tabular}{|c|c|c|c|c|}
\hline \multirow[t]{2}{*}{ Variables } & \multicolumn{2}{|c|}{ Practice of PMTCT } & \multirow[t]{2}{*}{$\operatorname{COR}(95 \% \mathrm{Cl})$} & \multirow[t]{2}{*}{ AOR $(95 \% \mathrm{Cl})$} \\
\hline & Yes Freq. (\%) & No Freq. (\%) & & \\
\hline \multicolumn{5}{|c|}{ History of previous antenatal care visit } \\
\hline Yes & $270(93.1))$ & 20(6.9) & $.36(.133, .963)$ & \\
\hline No & 29(82.9) & $6(17.1)$ & 1 & \\
\hline \multicolumn{5}{|c|}{ Knew mother to child transmission of HIV } \\
\hline Yes & $343(92.7)$ & $27(7.3)$ & $4.86(2.30,10.28)$ & $5.74(1.02,32.21)$ \\
\hline No & $34(72.3)$ & $13(27.7)$ & 1 & 1 \\
\hline \multicolumn{5}{|c|}{ Time of mother to child transmission of HIV } \\
\hline At least one & $256(94.5)$ & $15(5.5)$ & $6.53(2.86,14.88)$ & \\
\hline all & 69(94.5) & $4(5.5)$ & $6.60(1.99,21.76)$ & \\
\hline Don't know & $34(72.3)$ & $13(27.7)$ & 1 & \\
\hline \multicolumn{5}{|c|}{ Awareness on HIV counselling and testing } \\
\hline Yes & $368(91.5)$ & $34(8.5)$ & $7.22(2.42,21.49)$ & \\
\hline No & $9(60)$ & $6(40)$ & 1 & \\
\hline \multicolumn{5}{|c|}{ Discussed with husband about HIVIAIDS issues } \\
\hline Yes & 237(96.7) & $8(3.3)$ & $6.77(3.04,15.11)$ & \\
\hline No & $140(81.4)$ & $32(18.6)$ & 1 & \\
\hline
\end{tabular}

Table 4: Determinants of practice of prevention of mother to child transmission (PMTCT) of HIV/AIDS among pregnant women in Hossana town, South Ethiopia, March 2014.

Adjusted for knowledge of prevention of mother to child transmission of HIV/AIDS, time of mother to child transmission of HIV/AIDS, awared counselling and testing, discussion with husband about HIV and previous ANC visit.

\section{Discussion}

Increasing knowledge of ways in which HIV can be transmitted from mother to child and of the fact that the risk of transmission can be reduced by using antiretroviral drugs is critical to reduce motherto-child transmission of HIV. Prevention of mother to child transmission of HIV/AIDS services uptake is still low in Ethiopia due to low utilization of maternal health services such as antenatal care (34\%) and delivery care (10\%) [6]. If pregnant women are enrolled to maternal health services, they will receive services rendered for prevention of mother to child transmission of HIV/AIDS.
Consequently, attending maternal health service units will help women positively contributing for better utilization of services for prevention of mother to child transmission of HIV. Thus, this community based study attempted to assess knowledge of mother to child transmission and practice of services designed for prevention of mother to child transmission of HIV/AIDS and factors associated with the practice of pregnant women residing in Hossana town.

The proportion of pregnant women who know mother to child transmission of HIV/AIDS was found to be $88.7 \%$.Knowledge of mother to child transmission is nearly similar to the finding of Ashanti region, Ghana [10] and Addis Ababa TikurAnbessa and Zewuditu memorial hospitals, Ethiopia [11] which was $87.7 \%$ and $89.9 \%$ respectively. This finding is higher than that of Southwestern Nigeria [12] and Arbaminch, Ethiopia [13] which is $81.9 \%$ and $80 \%$ respectively. Moreover the proportion of knowledge of mother to child 
Citation: Hamdela B, Zekiewos F, Workneh T (2014) Knowledge on Mother to Child Transmission and Utilization of Services Designed to Prevent Mother to Child Transmission of HIVIAIDS among Pregnant Women in Hossana Town, Southern Ethiopia. J AIDS Clin Res 5: 396. doi:10.4172/2155-6113.1000396

Page 7 of 8

transmission is lower than that of Hawassa [5] and Southwestern Nigeria [1] which is $90.1 \%$ and $92.1 \%$ respectively.

Out of the participants who knew mother to child transmission of HIV/AIDS, 73.24\% knew at least one period of transmission whereas $19.73 \%$ of them knew the three periods (during pregnancy, labour and delivery and breast feeding). Knowledge on periods of HIV transmission is much lower than that of Addis Ababa in which $99.4 \%$ knew at least one period of transmission and 55.4\% mentioned all the three periods [11]. Similarly, knowledge of periods of HIV transmission in this study is also much lower than that of Arbaminch which accounts $55 \%$ and thought that there is a $100 \%$ risk of transmission of every conception. 86.5\% have the knowledge that HIV is transmitted through breastfeeding [13].The difference in mothers' knowledge regarding mother to child transmission of HIV and the period of its transmission depends up on the access to health information, availability of the services and the behaviour of health care providers. Besides, health improvement strategies with the focus on maternal and child health services including HIV/AIDS prevention and control program, prevention of mother to child transmission of HIV/AIDS program and millennium development goals (MDGs) activities could help for the improvement of knowledge regarding mother to child transmission of HIV/AIDS in different parts of the continent.

The screening process is a key tool in reducing mother-to-child transmission of HIV. Finding of this study reveals that $96.4 \%$ of the respondents are aware of HIV testing and counseling. 90.4\% were counselled and tested for HIV during current pregnancy. Of the tested, 99.2\% knew their HIV status. The proportion of pregnant women who were tested and knew their status is higher than that of Southwestern Nigeria [1] and Ghana [14] in which $66 \%$ and $76 \%$ of the respondents were aware of their HIV status through counselling and testing respectively. However, the proportion of mothers tested is a bit lower but the proportion of mothers shared the result of testing is higher than the study done at Hawassa university referral hospital which was $96 \%$ and $83.6 \%$ respectively [5]. This might be due to variation in attitude towards testing and receiving test result in different sociocultural contexts since fear of divorce, stigma and discrimination are supposed to be typical problems in cases when women are infected with HIV.

The proportion of women who received HIV testing is also much higher than that of nationwide EDHS [6] which reveal that $36 \%$ of women have ever been tested for HIV and received their test results. According to the nationwide survey, only $14 \%$ of women who gave birth in the two years before this survey received HIV counselling during antenatal care which is much lower than the finding of this study. This significant variation could be the result of participants' characteristics and the place where the studies are conducted. That means, this study involves pregnant women from urban area where better access to information and availability of the services exist while the findings of EDHS are from both urban and rural areas from women who have given birth in the last two years.

According to the findings of this study, the main reason for HIV testing was to know self-status (92.3\%) after getting counselling by health worker. Moreover, $98.1 \%$ of the respondents reported that they are satisfied with the services provided in the health facility. In contrary, the study finding from Ghana [14] reveals that HIV testing and counselling was high in some of the health facilities. Participants from those facilities disclosed that they had to do it because they were told it was compulsory so that they were coerced to do it. Midwives told them that if they do not do the testing, they could not deliver in that health facility. This difference in acceptance of testing between the two countries could be due to knowledge gap among women about the importance of testing and counselling during pregnancy. Besides, it might be the result of guidelines for interventions of some programs such as prevention of mother to child transmission of HIV/AIDS. For the effectiveness of PMTCT program, all women visiting maternal health service units are expected to undergo HIV testing so that they will have an opportunity to know their HIV status. Moreover, pregnant women are encouraged and counselled to be accompanied by their husband while visiting maternal health service units since male involvement is crucial for reproductive health programs. The attitude, skill and commitment of health workers for HIV testing and counselling might be another reason for mistreatment of clients.

Sharing of HIV test results among couples is important. Partners can support each other in cases when one or both of them are HIV positive. When one of the partners is positive, measures can be taken to prevent the other one from being infected. When they are both HIV negative, this knowledge encourages them to practice safer sex in order to remain HIV negative. Of those who were tested, $93.9 \%$ disclosed their test result for their partners however; the rest $6.1 \%$ did not disclose the result of testing. The proportion of pregnant women who did not share their test result is higher than the nationwide EDHS in which $2 \%$ of women did not share test result with their partner [6].This might be due to interventions to prevent and control HIV/ AIDS and access to information since the participants of this study were from urban areas. Finding of this study shows that women who knew mother to child transmission of HIV were nearly 6 times more likely to practice services rendered for prevention of mother to child transmission of HIV/AIDS as compared to women who did not know mother to child transmission of HIV[AOR $=5.74$, 95\%CI: 1.02, 32.21]. This implies that knowledge of mother to child transmission of HIV is the independent predictor for utilization of services rendered for prevention of mother to child transmission of HIV/AIDS. According to this finding, uptake of PMTCT of HIV/AIDS services can be improved by increasing the knowledge of pregnant women about mother to child transmission of HIV/AIDS.

Since this study was cross sectional, it is difficult to identify whether the exposure or outcome has happened first (egg and chicken dilemmas). Hence, practice of PMTCT of HIV/AIDS services might result in knowledge of mother to child transmission of HIV or vice versa.

\section{Conclusions and Recommendations}

Findings of this study indicated that more than three-fourth of pregnant women knew mother to child transmission of HIV/AIDS. Most pregnant women tested for HIV during current pregnancy and shared test result to their husband. Knowledge of Mother to child transmission was the independent predictor of utilization of PMTCT of HIV/AIDS services. Thus, health service planners, managers and providers should strengthen awareness creation activities on modes of HIV transmission in general and mother to child transmission in particular. Improving awareness of pregnant women about services available for PMTCT of HIV on mass Medias should be emphasized. Health care providers in maternal and child health service units should continue distributing information, communication and education materials and provide counselling on the importance of HIV testing during pregnancy. 
Citation: Hamdela B, Zekiewos F, Workneh T (2014) Knowledge on Mother to Child Transmission and Utilization of Services Designed to Prevent Mother to Child Transmission of HIVIAIDS among Pregnant Women in Hossana Town, Southern Ethiopia. J AIDS Clin Res 5: 396. doi:10.4172/2155-6113.1000396

Page 8 of 8

\section{Conflict of Interest}

The Authors declared that they have no conflict of interest.

\section{Authors' Contributions}

Belayneh Hamdela, Fregenet Zekiewos and Tigist Workneh: designed the project proposal. Belayneh Hamdela, Fregenet Zekiewos and Tigist Workneh: handled overall data collection process. Belayneh Hamdela: done statistical analysis and interpreted the data. Belayneh Hamdela: prepared the manuscript. Belayneh Hamdela, Fregenet Zekiewos and Tigist Workneh: Revised and approved the final manuscript.

\section{Acknowledgements}

We thank Wachemo University for providing the resources for this study without which this study would not have been possible. Our deepest gratitude goes to Hossana town administration office and Hossana town pregnant women for giving us crucial data without which this research would not have been realized. The data collectors and supervisors were also acknowledged for their honesty and proper data collection and follow up respectively. We are also grateful to the language editor, HabtemariamAmare (MA in English Literature and head, Department of English Language and Literature at Wachemo University) for his thorough reading and edition of this manuscript.

Finally, we are thankful to $\operatorname{Dr}$ Adane Haile, Research and publications directorate for his facilitation of the resources and faculty of medicine and health sciences instructors for their invaluable comments and supports throughout this study.

\section{References}

1. Olugbenga-Bello A, Adebimpe W, Osundina F, Abdulsalam S (2013) Perception on prevention of mother-to-child-transmission (PMTCT) of HIV among women of reproductive age group in Osogbo, Southwestern Nigeria. Int J Womens Health 5: 399-405.

2. Park JW, Yang TW, Kim YK, Choi BM, Kim HJ, et al. (2014) Ten years of experience in the prevention of mother-to-child human immunodeficiency virus transmission in a university teaching hospital. Korean J Pediatr 57: 117-124.
3. WHO, UNAIDS, UNICEF (2011) Global HIV/AIDS response: Epidemic update and health sector progress towards Universal Access.

4. Teshome M, Ali A, Dessie Y (2013) Determinants of Mortality among HIV Positives after Initiating Antiretroviral Therapy in Western Ethiopia: A Hospital-Based Retrospective Cohort Study. ISRN.

5. Abajobir AA, Zeleke AB (2013) Knowledge, Attitude, Practice and Factors Associated with Prevention of Mother-to-Child Transmission of HIV/AIDS among Pregnant Mothers Attending Antenatal Clinic in Hawassa Referral Hospital, South Ethiopia. J AIDS Clin Res 4:215.

6. Central Statistical Agency (Ethiopia) and ICF International (2012) Ethiopia Demographic and Health Survey 2011.

7. WHO (2007) Guidance on global scale-up of the prevention of motherto-child transmission of HIV: Towards universal access for women, infants and young children and eliminating HIV and AIDS among children.

8. Nguyen TA, Oosterhoff P, Ngoc YP, Wright P, Hardon A (2008) Barriers to access prevention of mother to-child transmission for HIV positive women in a well-resourced setting in Vietnam. AIDS Research and Therapy $5: 7$.

9. Lamina MA (2012) A survey of awareness and knowledge of mother-tochild transmission of HIV in pregnant women attending OlabisiOnabanjo University Teaching Hospital, Sagamu, Nigeria. Open Journal of Obstetrics and Gynecology 2: 98-105.

10. Boateng D, Kwapong GD, Agyei-Baffour P (2013) Knowledge, perception about antiretroviral therapy (ART) and prevention of motherto-child-transmission (PMTCT) and adherence to ART among HIV positive women in the Ashanti Region, Ghana: a cross-sectional study. See comment in BMC Womens Health 13: 2.

11. Jebessa S, Teka T (2005) Knowledge and attitude towards mother to child transmission of HIV and it's prevention among post natal mothers in TikurAnbessa and Zewditu Memorial Hospitals, Addis Ababa. Ethiop J Health Dev 19: 211-218.

12. Olugbenga-Bello AI, Oladele EA, Adeomi AA, Ajala A (2012) Perception about HIV testing among women attending antenatal clinics at Primary Health Centres in Osogbo, Southwest, Nigeria. Journal of AIDS and HIV Research 4: 105-112.

13. Haddis M, Jerene D (2006) Awareness of antenatal care clients on Mother-to-child transmission (MTCT) of HIV infection and its prevention in Arba Minch. Ethiop J Health Dev20:55-57.

14. Kwapong GD, Boateng D, Agyei-Baffour P, Addy EA (2014) Health service barriers to HIV testing and counseling among pregnant women attending Antenatal Clinic; a cross-sectional study. BMC Health Serv Res 14: 267. 